\title{
EPISTOLARIDAD Y NOVELA: AFÁN DE RIBERA Y CADALSO ${ }^{1}$
}

\author{
Jesús PÉREZ MAGALLÓN \\ McGill University
}

En un estudio reciente sobre la novela en la centuria ilustrada se dedican cuatro páginas a hablar sobre Virtud al uso y mística a la moda de Fulgencio Afán de Ribera (seudónimo probable de Bernardo de Ribera ${ }^{2}$ ), publicada en Pamplona, Juan Mastranzo, sin año, aunque en 1729. Se dice en dicho estudio: "Este folleto está lejos de la forma novelesca, pero tiene muchos elementos ficticios" (Álvarez Barrientos 1991, pág. 50). El mismo crítico silencia por completo las Cartas marruecas de Cadalso y menciona a su autor con finalidades muy diferentes. En otra monografía de la misma colección, dedicada a la prosa del siglo decimoctavo, se escribe sobre las Cartas marruecas: "El marco ficcional no es original [...]. La acción es mínima y los personajes de la fábula no tienen apenas individualidad y dan la impresión de ser unos esquemas abstractos" (Sánchez-Blanco, 1992, pp. 160-161) , dedicándosele un aislado párrafo a Afán de Ribera (pág. 34). Suertes desiguales corren los escritos de uno y otro a los ojos de los críticos mencionados. ¿Cuáles son los elementos ficcionales que llaman la atención en Virtud al uso y que, por el contrario, no hacen acreedora a la obra de Cadalso de un rincón en un estudio global sobre la novela dieciochesca? ¿Cuáles son los valores prosísticos de Cartas marruecas que no hacen merecedor al texto de Afán de Ribera sino de un simple párrafo en

1. Este trabajo ha sido posible a dos generosas becas recibidas de FCAR (del gobierno de Québec) y de SSHRC (del gobierno de Canadá). A ambos organismos, mi agradecimiento, más sincero.

2. Es lo que apunta Aguilar Piñal, pág. 54, quien proporciona además información bibliográfica de sumo interés, que viene a resolver algunos de los problemas planteados por Castañeda en el preliminar de su edición. De especial importancia es la existencia del manuscrito -aunque no sepamos si es el autógrafo- fechado en Granada, a 10 de Junio de 1729 , que se halla en la Biblioteca Nacional.

3. En cuanto a los personajes, algo parecido había escrito Quintana: "Esta falta viene de no haber dado Cadalso bastante variedad a los caracteres de los tres personajes principales, Gazel, Nuño y Bem-beley; y por consiguiente no haber en las cartas que se escriben recíprocamente aquella contraposición y diferencia necesarias para sostener el interés" (pág. 308). 
la monografía sobre la prosa? $\mathrm{O}$, por plantear con otras palabras la cuestión que va a ocuparme en las próximas páginas, ¿qué tienen que ver Virtud al uso y Cartas marruecas con la novela?

Recordemos brevemente el argumento de la obra de Afán de Ribera. En un "Prólogo al lector", D. Alejandro Girón confiesa haber ido a la Corte a resolver un pleito matrimonial; en el cuarto del mesón en que se aloja encuentra un pliego con el mismo título que el libro que tenemos entre las manos; lo lee, le interesa y decide continuarlo y acabarlo. El resultado final son tres cartas: dos del tal Alejandro Girón dirigidas a su hijo, el hermano Carlos del Niño Jesús, que contienen cada una de ellas diez llamados "Documentos", y entre ambas la respuesta del hijo a la primera de las cartas. Los "Documentos" contienen los consejos que el padre da al hijo sobre normas de conducta para tener éxito en la vida. Dichos consejos giran alrededor de la importancia de la falsa devoción como vía de acomodo social.

Álvarez Barrientos ha escrito que “donde en realidad está la ficción es en el prólogo, que es cuando el autor relata las circunstancias del escritor del folleto, don Alejandro Girón" (1991, pág. 50); en realidad, tenemos que suponer que el "Prólogo al lector" da la palabra al ficticio don Alejandro Girón, de modo que es el mismo personaje quien en primera persona relata las circunstancias en que ha surgido la obra. Lo que se puede tener como voz directa del autor se circunscribe a una dedicatoria y a una "Protesta del autor" con que se cierra el volumen. La ficción está en el prólogo, es cierto, pero no se termina ahí, sino que -con las características que iremos viendo-continúa a lo largo de toda la obra.

Empecemos por el principio. En el "Prólogo al lector" escribe D. Alejandro Girón que, encontrándose en el cuarto del mesón del Peine donde se acomoda cuando va a la Corte a seguir un pleito matrimonial, encontró un pliego de papel que había dejado su anterior habitante; y que, dudando sobre si continuar o no el pliego encontrado, se acordó de una noticia que oyó a su abuela:

y fue que en sus tiempos estaban tan validos los libros de cabalierías, que eran el único y total embeleso de las gentes; y para su destierro, los señores obispos tomaron diferentes providencias, ya enviando misiones, ya expidiendo cartas pastorales, pero nada aprovechó hasta que Cervantes tomó la pluma y escribió los libros de don Quijote. ¡Cosa rara, que lo que no pudo conseguir la desnuda verdad, voceada de los prelados y ministros eclesiásticos, fue reservado triunfo a la débil armadura y esfuerzo de una ingeniosa ficción! ${ }^{4}$.

Y a partir de esa reflexión se dice a sí mismo: "Veamos si lo que no puede vencer una desnuda verdad puede ser trofeo de una bien vestida ficción" (pág.

4. Fulgencio Afán de Ribera, Virtud al uso y mística a la moda, Madrid, Biblioteca Universal, Colección de los mejores autores antiguos y modernos, 1887, tomo CXIV, pág. X. Todas las citas remiten a esta edición, y en adelante sólo mencionaré entre paréntesis en el texto el número de página. 
XI). El párrafo copiado es digno de atención por varios motivos. En primer lugar, porque el Quijote recibe el mero nombre de "los libros de don Quijote"; en segundo lugar, por la lectura de la obra cervantina que se desprende de sus palabras; y en tercer lugar, por la perífrasis con que alude nuevamente al Quijote: "ingeniosa ficción". Acercándose a esos elementos, vemos que las aventuras del ingenioso hidalgo no reciben el título de novela sino de libros, cuya función o eficacia mayor ha consistido en desterrar de entre los hábitos de las gentes la afición a los libros de caballerías; pero esa dimensión social la ha conseguido una ingeniosa ficción, de efectos superiores a los de la mera verdad de prelados y eclesiásticos. La afirmación posterior al embarcarse el señor Girón en la continuación del escrito que encontró -escribir una "bien vestida ficción" para desterrar a estos bergantes "que hacen trato de la virtud, unos para comer, otros para gobernar y otros para suponer" (pág. X)- es prueba evidente de que su obra quiere situarse en la estela abierta por la novela de Cervantes. Pero no en el sentido que más tarde se daría a la misma, sino en una de sus más elementales interpretaciones: el destierro o la erradicación de algo por medio de la sátira. Ahora bien, el que nos encontremos ante una lectura limitada (por no decir equivocada) del Quijote no implica que no se reconozca el texto cervantino como novela ni que, al calificar su obra de "bien vestida ficción", Afán de Ribera no esté intentando escribir, precisamente, una novela.

No es ésa la única alusión a Cervantes. Ya en Carta I, Alejandro Girón alude a "papelillos y librotes [...] que todos conspiran en formar un caballero andante, deshacedor de tuertos; y allende de esto, ninguno le señala renta para comer" (pág. 14). La interpretación que se desprende de sus palabras parece evidente: mucho se ha escrito y escribe sobre cómo llegar a ser una persona "ideal" (en ese sentido parece aludirse a don Quijote), pero nadie da consejos sobre cómo medrar materialmente en la vida social. Y ese va a ser el objetivo que persigue el autor de las epístolas, adoctrinar a su hijo -a quien tiene por tonto sustancial (pág. 15) - para que llegue a llevar una "vida mejor que canónigo" (pág. 14).

Ignoro hasta qué punto esa hipocresía beata que Afán de Ribera pretende desterrar constituía un fenómeno de dimensiones sociales importantes; ningún documento parece atestiguar en España una situación similar a la que se produjo en Francia bajo Luis XIV con el movimiento de los devotos, a los que Molière arrojaría acerados dardos en algunas de sus comedias y quien, a su vez, sería blanco predilecto de los ataques de aquéllos ${ }^{5}$. Lo cierto es que al menos dos textos puede traerse a colación para explicar el interés de Afán de Ribera en el tema de la hipocresía devota. En el Directorium Inquisitorum (Avignon, 1376), Nicolau Eymerich escribe:

5. Existe un estudio de Yves Cabanes, que cataloga Aguilar Piñal y se encuentra en el Institut d'Études Hispaniques, en París, bajo la signatura 21-m-1. Desgraciadamente no he podido verlo. Tampoco he logrado ver el que promete ser muy interesante artículo de Maria Grazia Profeti. 
Il ya ceux qui marchent la tête baissée en regardant le sol, et ceux qui avancent les yeux au ciel. Ils ont des mots d'humilité plein la bouche, et l'apparence de la sainteté, comme des sépulchres blanchis et dorés renfermant des cadavres. Car en dedans ils sont pleins d'orgueil, de luxure, de gloutonnerie, d'envie et de vanité: ceux qui les connaissent le savent bien. Avec leurs airs de sainteté ils infectent quantité de gens et éludent ainsi le jugement de l'Inquisition (pág. 129) ${ }^{6}$.

El objetivo evidente de Eymerich es proporcionar criterios para intentar distinguir a los que, pese a las apariencias -es decir, a los intentos por parecer dechados de religiosidad-deben ser perseguidos por el Santo Oficio.

En otro contexto y con intención claramente diferente, es lo mismo que Molière atribuye a su Dom Juan, cuando éste afirma que "I'hypocrisie est un vice à la mode, et tous les vices à la mode passent pour vertus. Le personnage d'homme de bien est le meilleur de tous les personnages qu'on puisse jouer aujord'hui, et la profession d'hypocrite a de merveilleux avantages. C'est un art de qui l'imposture est toujours respectée" $(\mathrm{V}, 2)$, y algo después: "Combien crois-tu que j'en connaisse qui, par ce stratagème, ont rhabillé adroitement les desordres de leur jeunesse, et, sous cet habit respecté, ont la permission d'être les plus méchants hommes du monde?" $(\mathrm{V}, 2)$; una hipocresía que cobra la forma de virtud (o beatería) cristiana: "Il [Dieu] a inspiré à mon âme le dessein de changer de vie, et je n'ai point d'autres pensées maintenant que de quitter entièrement tous les attachements du monde, de me dépouiller au plus tôt de toutes sortes de vanités, et de corriger désormais par une austère conduite tous les dérèglements criminels où m'a porté le feu d'une aveugle jeunesse" $(\mathrm{V}, 3)$, responde Dom Juan a Dom Carlos cuando éste le reclama que respete su matrimonio con Done Elvire. Quiere esto decir que, si tal vez no es cierto que existiera ese vicio social que precisaba desengaño o destierro, sí es verdad que existe una cierta tradición sobre el tema de la hipocresía beata, lo que situaría la obra de Afán de Ribera en el ámbito de la ficción literaria más que en el de la crítica social. No debe olvidarse la obra de Tirso, Marta la piadosa, ni que años después Moratín volvería al tema con La mojigata.

Al. concluir la Carta III resume don Alejandro Girón sus enseñanzas de esta chusca manera: "Finalmente, hijo mío, estos documentos se reducen a que consigas la felicidad que contienen estos dísticos de Cicerón, que me los tradujo de latín en castellano cierto amigo músico, y dicen así: Tenga yo salú / con paz y quietú, / dinerillos que gastar, / vestir y calzar, / y ándese la gaita / por el lugar" (pp. 84-85). Sobre estas palabra escribe Álvarez Barrientos: "La cita puede parecer anecdótica, pero en ella se encuentra, y muy tempranamente, una de las características ya señaladas de la novela y de la condición humana en el siglo XVIII: el objeto único de ser feliz, que las novelas expondrán adecuadamente durante la centuria, con un fuerte componente moralizante católico, que denuncia el uso de las virtudes morales de forma social" (1991, pág. 52). Lo que no parece percibir el crítico es que esa "felicidad" no es precisamente la

6. Debo esta fuente a la amabilidad y sabiduría de mi colega David A. Boruchoff. 
que desearán los ilustrados, y que el contenido irónico es más que evidente. Sin embargo, la variedad de elementos satíricos va más allá de censurar la hipocresía beata y de resaltar esa variante del carpe diem horaciano. La crítica de los mayorazgos, las ironías sobre el prurito de los tratamientos y jerarquías entre los nobles, las pullas a los médicos - pero también su defensa, los comentarios acerados sobre la Academia de la Lengua, las indirectas sobre cierto tipo de clérigos, el temor a discutir abiertamente de temas relacionados con la monarquía o la imprudencia -coyuntural- de meterse en polémicas con médicos y astrólogos son temas que están presentes en la obra. "El valor informativo de la Virtud al uso, para el conocimiento de las costumbres españolas, es terminante y de inapreciable valor por lo que a la picaresca de los beatos se refiere" (Castañeda, 1952, pág. 16). En cierto sentido, pues, la obra de Afán de Ribera también trata, a su manera, del carácter nacional, aunque destacando en él sólo un aspecto central -la mojigatería religiosa- y careciendo de la amplitud y profundidad con que Cadalso se acercará a él en su obra. La técnica que utiliza, semejante a la que, salvando las distancias, empleó Erasmo en su Elogio de la locura, consiste en defender lo contrario de lo que piensa. No obstante, Virtud al uso fue incluida en el Index librorum prohibitorum que redactaron los jesuitas Cassani y Carrasco en 1747, a pesar de la "Protesta del autor" que figura en la edición y del subtítulo que llevaba la obra: "Destierro de la hipocresía en frase de exhortación a ella. Embolismo moral, en el que se epactan las afirmativas proposiciones en negativa, y las negaciones, en afirmaciones".

Por su parte, escribe Cadalso en la Carta LXI de las Cartas marruecas: "En esta nación hay un libro muy aplaudido por todas las demás. Lo he leído, y me ha gustado sin duda; pero no deja de mortificarme la sospecha de que el sentido literal es uno, y el verdadero es otro muy diferente. Ninguna obra necesita más que ésta el diccionario de Nuño [...] Lo que hay debajo de esta apariencia es, en mi concepto, un conjunto de materias profundas e importantes" (Cadalso, 1983, pág. 224, el subrayado es mío). ¿A qué se refería el coronel José de Cadalso con estas palabras? ¿En qué sentido -metafórico o simbólico, o sea, verdadero, pues no literal- pensaba al escribir estas líneas ${ }^{7}$ ? ¿Qué materias profundas e importantes veía él en el Quijote y que habían escapado a la lectura de quienes aplaudían o habían aplaudido el libro? ¿Qué significado percibía en la obra de Cervantes ${ }^{8}$ ?

Una ayuda puede tal vez encontrarse en la "Introducción" que antecede al texto de las Cartas. Ahí escribe su autor: "Desde que Miguel de Cervantes compuso la inmortal novela en que criticó con tanto acierto algunas viciosas costumbres de nuestros abuelos". ¿Podía pensar en ese contenido crítico al redactar su Carta LXI? Tal vez. Pero, ¿no forma parte esa visión crítica de la sociedad de su tiempo de la interpretación del Quijote ya aceptada en el XVIII? Basta recordar lo que había escrito Mayans en Vida de Miguel de Cervantes: se

7. Es la misma pregunta que podría hacerse cuando Mayans escribe que le parece necesario escribir un libro muy crecido sobre "el alma verdadera desta fingida historia" (1972, pág. 138).

8. Sobre Cervantes y Cadalso son de consulta obligada Ramírez Araujo, Roges y Pires. 
trata de "una sátira la más feliz que hasta hoy se ha escrito contra todo género de gentes" (1972, pág. 127). La respuesta, por tanto, quizá venga mejor por otro camino: ¿Qué sentido tiene la propia obra de Cadalso en que se contienen las líneas que citaba más arriba? ¿Qué son las Cartas marruecas?

El "editor" del texto -que, como Afán de Ribera, asegura haberle venido a las manos-, autor de la "Introducción", lo afirma con toda claridad: "Yo no soy más que un hombre de bien, que he dado a luz un papel que me ha parecido muy imparcial, sobre el asunto más delicado que hay en el mundo, cual es la crítica de una nación" (pág. 82); y aún antes había sostenido: "Estas cartas tratan del carácter nacional, cual lo es en el día y cual lo ha sido" (pág. 81). Pero todavía antes había dicho: "Me he animado a publicarlas por cuanto en ellas no se trata de religión ni de gobierno" (pág. 81). Crítica, sin duda; crítica-reflexión sobre el carácter nacional sin entrar en religión o gobierno, como también don Alejandro le había sugerido a su hijo: "En cosas de monarquía no has de hablar palabra; si oyeres algo de esto, decir que nos hemos de morir, y que sólo nos toca el obedecer" (pág. 61).

Aparte de lo que otros críticos han aportado ya en cuanto al análisis ideológico de las Cartas marruecas, creo que la presencia de Cervantes puede indicarse también en otra dirección". Si la lectura que del Quijote hace Cadalso capta, como intuyo, la dualidad entre lo sublime y lo vulgar, nada podría concretarse mejor en su obra que la oposición entre la valoración que hace de lo sustancial -LO SUBLIME- y lo accidental -LO VULGAR. Esa dualidad -o los dos términos de una tensión dialéctica que dejará abierta una posible síntesis al modo cervantino: el futuro -se refleja en varias contraposiciones presentes a lo largo del texto: cosmopolitismo-nacionalismo, Ilustración-tradición, imparcialidad-subjetividad, pasado-presente, España-Europa y, muy especialmente, en otra oposición que no se ha subrayado debidamente, CastillaEspaña. Las Cartas marruecas llaman la atención por su densidad filosófica, política e ideológica, lo que la convierte en una de las obras pioneras y esenciales en la historia de nuestro pensamiento. Abellán, con muchas razones, la ha incluido en la literatura que trata el "problema de España” (pág. 793). Pero esa inclusión no explica suficientemente el hecho clave de que aquí hablamos: ¿por qué elegir una forma fictiva en lugar de un tratado?

Resulta evidente, por tanto, que ambos autores - Afán de Ribera y Cadalso- pretenden escribir algo útil. Y ese podría ser un elemento a considerar a la hora de discutir (más bien negar) el carácter novelesco de los dos textos. Pero, además del tópico horaciano, o junto a él, las primera elaboraciones que se producen en España sobre la novela como género digamos independiente tienen muy presente esa dimensión útil o provechosa de la ficción. Así, Mayans (1757, tomo II, pág. 332) escribe que la novela es "una fingida narración de sucesos circunstanciados para instrucción de quien los oye o los lee", y en esa

9. Pueden verse los trabajos de Sebold (1974, pp. 198-237), Glendinning (1962, pp. 86-101), Maravall y Abellán (pp. 794-806). 
dirección le seguirán quienes traten del tema ${ }^{10}$. Sería inimaginable de otra manera. Así lo había hecho Cervantes y así lo harían los seguidores ingleses de Cervantes. Que lo útil sea moralidad expresa, o reflexión dentro de la ficción sobre el carácter nacional, o que se desprenda claramente del curso de los acontecimientos o del tema de la obra, no debe ser el elemento de juicio central para valorar lo novelesco de un texto.

No puede ser casual que ambos autores se remitan en sus respectivos prólogos a la obra de Cervantes ${ }^{11}$, y tampoco deja de ser significativo que dos textos que, por otra parte, tienen en común el estar construidos en forma epistolar, aparezcan bajo la advocación del creador de la novela moderna. (Aunque, claro está, eso no les garantiza ningún éxito en sus realizaciones). Pero Cadalso no se limita a mencionar a Cervantes y a calificar Don Quijote de novela, sino que también se refiere a las críticas "que llevan el nombre de Cartas" (pág. 77), para aludir al género como "ficción" (pág. 78). Así, a los ojos de Cadalso, su obra es una ficción crítica, lo mismo que Virtud al uso es, en palabras de su principal narrador, una "bien vestida ficción" para enseñar a medrar a base de hipocresía beata. Está claro, pues, que ambos textos expresan la conciencia de una finalidad que no es la previsible en una novela, una función práctica -la tópica utilidad horaciana- (aunque debe seguir teniéndose presente el modo en que se lee lo que sí es una novela, el Quijote), pero también la de una forma agradable: la ficción, que en ambos casos cobra la forma de un intercambio epistolar.

Afán de Ribera no proporciona ninguna explicación de por qué ha elegido la forma epistolar para su texto, pero Cadalso sí lo explica: "El mayor suceso de esta especie de críticas debe atribuirse al método epistolar, que hace su lectura más cómoda, su distribución más fácil, y su estilo más ameno, como también a lo extraño del carácter de los supuestos autores" (pág. 78). Así pues, para Cadalso comodidad, facilidad, amenidad y extrañeza resumen las virtudes del método. Pero deja de mencionar algo que viene dado al hablar de "los supuestos autores": se trata de narraciones en primera persona con tanta diversidad de narradores como autores de cartas existan (y con tanta multitud de voces como los narradores quieran incluir en sus misivas). En otras palabras, la elección de un punto de vista interno en primera persona con multiplicidad de narradores permite, desde ese aspecto técnico, la creación de un mosaico cuyos fragmentos sólo son verdaderamente recompuestos o recreados en la mente del lector. La carta, a causa de su propia realidad material -objeto que media entre partes separadas- puede llegar o no llegar, extraviarse, permanecer sin enviar por razones cualesquiera. Por otra parte, la flexibilidad de la carta autoriza a incluir desde la exposición minuciosa de una reflexión personal hasta la narración de un episodio relativamente autónomo, pasando por apuntes históricos, aforismos más o menos desarrollados, fragmentos líricos; muy en especial, como es

10. Véanse los trabajos de Étienvre, Álvarez Barrientos (1983 y 1987-88) y Pérez Magallón (1991, pp. 164-174).

1i. Que no son una excepción puede comprobarse en las palabras de Olavide que cita Sebold en el artículo que se recoge en el presente volumen. 
el caso de las Cartas marruecas, para la inclusión de otros textos que no constituyen propiamente la carta, aunque se integran en ella. Pero sobre todo es un instrumento inmejorable para poner de relieve todo lo subjetivo que cada uno de los yos narradores pretende expresar. La diversidad de yos y de voces narrativas aparece, pues, como un recurso absolutamente apropiado para la composición de un texto lleno de diferentes perspectivas y, como veremos más abajo, de carácter dialógico ${ }^{12}$.

Ahora bien, ¿en qué medida la carta ayuda a sostener el interés, a hacer avanzar la acción, a preparar un desenlace? En el caso de Virtud al uso, su función queda muy limitada por el número mismo de cartas: por ellas sabemos que Carlos del Niño Jesús ha puesto en práctica los consejos de don Alejandro y que el resultado no puede ser más esperanzador. En cuanto a las Cartas marruecas, las diferentes epístolas -a pesar de la falta de fecha y de la problemática ordenación de las mismas (Glendinning, 1971)-proporcionan una información esencial respecto a la acción: la progresiva integración de Gazel en el mundo que ha venido a observar y, con ello, el avance en su propio aprendizaje; la profundización en la relación entre Gazel y Nuño -caso notable de una amistad entre $e l$ cristiano y el moro-; el enriquecimiento reflexivo y la ampliación generalizadora de Ben-Beley desde su retiro en Marruecos; incluso el comienzo de una relación sólo escrita entre Nuño y Ben-Beley. Dada la elección cadalsiana, la epístola actúa como vehículo imprescindible del tipo de desarrollo narrativo y reflexivo que la acción requiere.

En consecuencia, el problema parece no ser tanto si la obra es ficción o no, sino cuánta ficción hay en ella; y aún más allá, si en el conjunto ficticio de la obra hay suficientes elementos novelísticos como para considerarla novela. Porque lo que hace fundamentalmente don Alejandro Girón, como su hijo el hermano Carlos del Niño Jesús, no es narrar, ni describir, ni transcribir diálogos de otros personajes, sino aconsejar el uno y responder a los consejos el otro. El contenido didascálico de la obra y el sentido irónico de la misma no parecen haber dejado margen al desarrollo de lo novelístico. La unidireccionalidad del discurso irónico es absoluta. El caso de Cadalso es bastante diferente. No sólo todo el texto está construido a base de las numerosas cartas de tres personajes diferenciados, sino que éstos no se limitan a exponer comentarios teóricos sobre la realidad; los tres -cada cual a su manera-viven, actúan, hablan, narran. De todo modos, y como punto de partida provisional, parece evidente que un libro de normas de conducta o un conjunto de escritos críticos sobre un país no pueden ser tenidos por novelas.

Llegados a este punto es necesario meterse en el espinoso tema de decir algo sobre qué es la novela. Pero para situarnos creo que bastará una cita de Bourneuf y Ouellet:

12. Para un estudio de la novela enistolar y la epistolaridad en general, deben verse la obra de Altman, aunque ni ella ni otros estudiosos del género, como Singer, dedica una sola palabra a Cadalso. 
El carácter "abierto" del género, que permite cambios recíprocos, su aptitud integradora, siguiendo dosificaciones diferentes, de los elementos más dispares documentos en bruto, fábulas, reflexiones filosóficas, preceptos morales, canto poético, descripciones, en pocas palabras, su ausencia de fronteras, contribuyen a su éxito: cada uno acaba por encontrar aquello que busca, y a asegurarle larga vida: su extrema ductilidad le ha permitido triunfar de todas las crisis. Estos mismos rasgos hacen aventurada toda tentativa de definir el género (pág. 31)

Sí, toda tentativa de definirlo es aventurada. Pero los mismos autores mencionan algunos rasgos: la novela es narración, es decir, alguien relata algo, cuenta una serie de acciones; narra una historia, o sea una serie de sucesos encadenados en el tiempo desde un principio hasta un fin; la historia narrada es ficticia, aunque el problema que suscita la relación entre ficción y realidad no es para saldarlo en tres líneas; la narración de la historia ficticia debe tener una cierta construcción, ritmo y tono, lo que diferencia la novela del relato o del cuento.

Volvamos entonces a la pregunta inicial: ¿qué tienen que ver Virtud al uso y Cartas marruecas con la novela? Escribe Álvarez Barrientos que llevar a cabo su crítica de las vivencias hipócritas de los católicos "supone una previa y atenta labor de observación: el aspecto, indumentaria y gesto del místico a la moda; de la 'desvergüenza con los ojos bajos'; de la conversación con hombres críticos" (pág. 51), pero ahí parece terminar su indagación. En realidad, la labor de observación se refleja en dos niveles diferentes. Por una parte, en la captación de los elementos externos de la realidad, aunque sin alcanzar la minuciosidad de detalle que caracterizará a escritores algo posteriores como Torres Villarroel o Isla. No obstante, esa atención observadora se pone de manifiesto en algunos, pocos, pasajes. Así, por ejemplo, cuando don Alejandro le aconseja a su hijo cómo arreglar su habitación le dice: "El adorno de tu cuarto será un fiel testigo de tus buenos ejercicios; y así, las paredes estarán llenas de estampitas, y a proporcionados trechos algunos cilicios de diferente hechura [...]. Tendrás dos camas: la una será una desnuda tarima, y por cabecera una piedra, como medio umbral de puerta, y encima una calavera; pondrás sobre la cama un cruzón de quince pies de largo, con su corona de espinas $[\ldots]$. La otra cama constará de tres o cuatro colchones, sábanas de delgado lino y cabeceras de ruan o cambray" (pág. 30). Añade después que en el aposento debe tener "un altarito, aseadamente alhajado, no con ricas preseas, pero con cositas muy curiosas y artificiosamente colocadas" (pág. 31). Descripciones semejantes pueden encontrarse en la carta que escribe Carlos del Niño Jesús a su padre. A la propuesta del hijo de cortarse el pelo a rapa terrón, el padre le contesta que sí, "pero sin afectación de guedejitas" (pág. 81). Vale la pena también fijarse en el proyecto de vestimenta sobre el que le pide consejo a don Alejandro: "Me parece será muy del caso el vestirme de sayal franciscano, en traje de abate, en esta forma: la collarina negra y mi cuellecito almidonado con sus polvitos de color azul celeste, capa, casaca, chabarreta y calzón del dicho sayal, y mi sombrero a tres vientos, también de contextura franciscana" (pág. 49), a lo que el padre opone: "Vístete de paño bueno, tu valoncita sin 
encajes, a lo viudo y estilo antiguo, tu sombrero negro sin forro, con un cordoncito, como sombrero de fraile" (pág. 81).

Pero la observación se constata asimismo en lo que se percibe como cierta perspicacia psicológica para aproximarse al carácter de ciertos tipos a los que, por otro lado, no se describe:

Solicita con maña conocer los genios: al vano, alábale su bizarría; al místico, pondérale los bienes de la limosna; al compasivo, represéntale con viveza, o tu failta de los más precisos, o las ajenas, extremas o graves; y a río revuelto, ganancia de pescadores; al liberal, empeñarlo a que empiece; al miserable, decirle que todos le tienen por mezquino, pero que tú has sacado la cara por él cuantas veces lo has oído, y que en su defensa has dicho que no tienen razón, y que acusan neciamente su loable economía, y que no ser pródigo es virtud, como también el dar en las ocasiones es liberalidad (pág. 36)

Es evidente que consejos como los que da don Alejandro no salen sin una constante y atenta observación de los modos y maneras en que ciertas personas -cierta clase de personas- reaccionan o actúan ante los demás. Algo semejante podría decirse de afirmaciones generales como la de que "hay unos tontos por fuera, otros por dentro, y otros por dentro y por fuera" (pág. 54), para explicar seguidamente las diferencias entre ellos. La misma clase de perspicacia se evidencia al hablar de los mayorazgos, los segundones, las monjas, los clérigos, etc.

Por otra parte, la historia en el texto se reduce a lo siguiente: don Alejandro le escribe a su hijo dándole consejos; éste los recibe y los pone en práctica; don Alejandro le vuelve a escribir para darle más consejos todavía. En cuanto a la narración de sucesos, forzoso es decir que se circunscribe a dos episodios que Carlos del Niño Jesús le cuenta a su padre como testimonio de la puesta en práctica de los consejos contenidos en los diez documentos que acompañan la primera carta. Tratando de darle prueba a su padre de sus progresos en el arte místico-hipócrito-bribónica, le escribe: "y en prueba de ello referiré a su merced lo que habrá ocho días que me sucedió" (pág. 41), pasando a contarle una experiencia habida en "cierta casa de la Plazuela de la Cebada" (pág. 41) con motivo de una procesión el día de San Isidoro. Con la misma finalidad, y en relación con la necesidad de improvisar a que se ha visto obligado, dice: "yo le referiré cómo sucedió" (pág. 47), y le cuenta su breve experiencia con una viuda desconsolada. Ahí, a pesar de nuestros deseos, se termina el contenido "narrativo" de Virtud al uso.

Respecto al ámbito temporal, sólo sabemos que han transcurrido seis meses desde que Carlos del Niño Jesús recibió la carta de su padre; que le responde después del 22 de Mayo de 1729 -puesto que incluye una nota con esa fecha-, y que don Alejandro escribe su segunda y última carta el 10 de Junio del mismo año. Esas son todas las referencias temporales que se proporcionan en el texto. Y en cuanto al espacio, don Alejandro data su última carta en Granada y debemos suponer que su hijo se encuentra en Madrid. 
Con esos elementos, resulta evidente que en el texto de Afán de Ribera lo monitorio ocupa la mayor parte del texto (de ahí la abrumadora mayoría del uso de imperativos y de futuros en las cartas de don Alejandro) y que los pocos episodios narrativos se encuentran en la carta de Carlos del Niño Jesús, quien responde al padre y, por lo tanto, puede y debe contar algo para demostrar cómo está poniendo en práctica los consejos recibidos. Pero el hecho mismo de que sólo haya tres cartas, y de que las dos de don Alejandro estén formadas por documentos instructivos, apenas permite el conocimiento y, por supuesto, la evolución de los personajes. Otra limitación evidente la constituye la ausencia de voces narrativas diferentes a las de don Alejandro y su hijo. La misma extensión de la obra es un claro límite para todo lo que podíamos considerar como desarrollo narrativo. Lo que tenemos es, pues, un discurso epistolar con ciertos matices (Altman, pp. 117-142).

$\mathrm{Al}$ acercarse a las Cartas marruecas, sin embargo, habría que tener presente lo que sugiere Conroy Jr. sobre Montesquieu: "To see Montesquieu's book principally as a novel requires a new attitude toward the text itself' (pág. 30). Lo mismo que ha sucedido con la obra de Cadalso, la actitud tradicional, como he señalado más arriba, ha sido analizarla o estudiarla por su contenido político, filosófico o social. Y ese es el enfoque que hay que modificar para un estudio algo distinto sobre el tipo de texto al que nos enfrentamos. La crítica ha señalado ya en las Cartas Marruecas numerosos rasgos que son específicamente novelísticos. Sebold (1974, pp. 232-233) indicó algunos hace tiempo. Arce (pág. 39) resume esos rasgos en las categorías del diálogo, la descripción y la narración, excluyendo de lo novelístico la exposición. Baquero Goyanes matiza la descripción cadalsiana para considerarla como "toques descriptivo-costumbristas" (pág. XLIII). Matices aparte, lo cierto es que la multitud de episodios narrativos, en boca de Nuño o de Gazel, quien llega a decir de lo que él mismo ha descrito: "hermano del que acabo de retratar en esta carta" (pág. 120, el subrayado es mío), de aparición de personajes y de transcripción de diálogos es mucho más que un mero aditamento para enmarcar el discurso expositivo de carácter ideológico.

Sin embargo, uno de los aspectos por los que Baquero Goyanes insiste en que Cartas marruecas no es una novela es la ausencia de intriga; en otras palabras, porque la historia (o diégesis) es demasiado simple y, tal vez, poco interesante. Para ello, tanto él como otros críticos reducen al mínimo la trama de la obra. Quintana la resumía así: "Cadalso supone que un berberisco de Marruecos viaja por España y da parte a otro africano amigo suyo de las observaciones que va haciendo en la historia, costumbres y modales de sus habitantes" (1803, pág. 308). Baquero Goyanes sigue comparando la obra de Cadalso con la de Montesquieu para señalar que ésta tiene algo más de intriga por los sucesos del serrallo, aunque ni siquiera al francés le reconoce que su obra sea una novela ${ }^{13}$. Lo cierto es que la crítica de Lettres persanes no ha

13. "Las Lettres persanes no constituyen propiamente una novela, pero se acercan bastante a lo que entendemos por tal [...]. Hay, por lo tanto, una muy flexible estructura novelesca que, como el mismo autor vio, le permitió manejar toda clase de digresiones" (Baquero Goyanes 1981, pág. XXXIV). 
sostenido su carácter novelesco sólo por esa intriga y sí ha insistido en los últimos veinte años en que se trata de una novela en el pleno sentido de la palabra. El mismo Montesquieu, en Quelques réflexions sur les Lettres persanes, afirmó que se trataba de "une espèce de roman" (Montesquieu 1875, tomo I, pág. XXXIV), explicando ahí por qué lo era. Además, y eso me parece lo más importante, considerar que la variedad e interés de la intriga es piedra de toque definitiva para otorgar etiqueta de novela a un texto es atarse en exceso a una concepción anclada en el siglo XIX. ¿Qué intriga existe en La muerte de Virgilio o en La jalousie, por poner sólo dos ejemplos?

La solución que ofrece Baquero Goyanes para calificar el género de las Cartas marruecas es llamarla "una especie de miscelánea o silva" (pág. XXXVI), idea que desde luego no se puede decir dé razón de lo que es el texto cadalsiano. Tanto él como quienes se niegan a aceptar que la obra de Cadalso es una novela parecen mostrar un concepto harto rígido de lo que debemos entender por tal ${ }^{14}$. Y, sobre todo, parecen olvidar dos cosas esenciales de las que ya he hablado: primero, cómo se concibe la novela en la época; y segundo, las especiales características de la novela epistolar. Dichos críticos afirman que existen elementos novelísticos, pero niegan el carácter de novela. Planteemos la cuestión de otra manera. Un texto en el que tres personajes ficticios (de los cuales, dos están claramente individualizados) intercambian cartas a lo largo de un período determinado de tiempo, cuentan en ellas todo lo que les ocurre, lo que ven, lo que viven, lo que piensan, lo que sienten, lo que otros les cuentan, lo que leen, etc.; un texto con multitud de voces en el que al menos uno de los personajes -el más joven- sufre una más que evidente evolución, y que termina cuando este último debe marcharse, dejando en el aire la posibilidad de que esa correspondencia continúe desde su lugar de residencia, ¿qué es sino una novela?

Recientemente, Sebold ha escrito un artículo bajo el título de La novela social de Cadalso ${ }^{15}$. En él ha subrayado un aspecto ya señalado con anterioridad al estudiar otras novelas dieciochescas, pero aplicándolo a la obra caldasiana: la representación de costumbres de personajes individuales como algo decisivo en su carácter novelístico; asimismo, ha rebatido a quienes niegan que las Cartas marruecas sean una novela por "la aparente falta de argumento", recordando sintéticamente que en el tex to hay "abundante información argumental para la historia íntima de personajes como Gazel y Nuño Núñez", y que el mismo Cadalso en la "Nota" al final de la obra habla de las vidas de los personajes después de su intercambio epistolar. Sobre todo me parece esencial que traiga a colación muy oportunamente "la poética novelística cadalsiana". El caos del mundo -la realidad- sólo puede imitarse a través del caos y desorden que reina en las Cartas marruecas, como se explica en la Carta

14. Es obligado mencionar aquí que la única persona que ha considerado sistemáticamente las Cartas marruecas como novela (novela epistolar-racionalista, la califica) ha sido Zavala, en un artículo lleno de agudas sugerencias.

15. Gracias a la proverbial amabilidad de Russell P. Sebold, he tenido acceso a su texto antes de su publicación. 
XXXIX, así como por la integración en semejante caos de lances puramente novelísticos. Finalmente, Sebold se pregunta por la especie de novela dentro del género para afirmar: "Trátase al parecer de cierta clase de novela epistolar costumbrista o social", para acabar señalando la vinculación que se da entre costumbrismo y novela, presente en la obra de Cadalso como en toda la ficción desde Isla hasta Galdós.

Creo, sin embargo, que hasta el momento no se ha insistido suficientemente en algunos aspectos: la evolución de al menos dos yos ficticios individualizados en un discurrir temporal nítidamente inscrito en la obra, y el carácter dialógico o polifónico de la misma.

Podría aplicarse a los personajes de Cartas marruecas lo que Jean Goldzink dice de Lettres persanes: " $n$ 'ont jamais fait rêver à des pesonnages, à des destinées, à des aventures; elles imposent un style et des idées" (pp. 91-92). Y digo que "podría" porque no estoy tan seguro de que los destinos de Gazel, Nuño Núñez y Ben-Beley no seduzcan al lector como los de tales seres de ficción; sí coincido en que sus "aventuras" no son precisamente lo que nos seduce, aunque existan y en algunos momentos uno deseara que prosiguieran. Pero ¿quiere ello decir que el lector no tiene ningún interés en saber, en seguir lo que le sucede a Gazel? Cartas marruecas no carece de acción, aunque no se trate obviamente de una novela de aventuras ${ }^{16}$; los avatares de Gazel son el eje que estructura toda la obra y, en cierto sentido, podríamos afirmar que se trata de una novela de aprendizaje o, en otros términos, que Cadalso ha construido a través del intercambio epistolar entre tres personajes una novela didáctica sobre cómo debe educarse el joven en la sociedad de la época y, particularmente, qué valores deben constituir la base de su educación. Algo así apunta Zavala (pág. 350), aunque sin darle toda la importancia estructural y organizadora que tiene. Pero, además, ello demuestra el concepto de educación que sostiene el texto: es universal y no acepta límites religiosos o raciales.

La utilidad de Cartas marruecas va, por lo tanto, más allá de ser una reflexión sobre el carácter nacional, pues Gazel precisamente va a descubrir a lo largo de su viaje y en el contacto con Nuño un nuevo modo de hacer frente a la vida, ya que lo aprendido no tiene, desde la perspectiva de Cadalso, fronteras nacionales. Baste repetir lo que le escribe Gazel a Nuño en la última carta: "Mi familia acaba de renovar con otra ciertas disensiones antiguas, en las que debo tomar partido, muy contra mi genio, naturalmente opuesto a todo lo que es facción, bando y parcialidad [...]. Siento dejar tan pronto tu tierra y tu trato. Ambos habían empezado a inspirarme ciertas ideas nuevas para mí hasta ahora, de las cuales me había privado mi nacimiento y educación, influyéndome otras que ya me parecen absurdas, desde que medito sobre el objeto de las conversaciones que tantas veces hemos tenido" (pp. 300-301). El cierre de la novela, por tanto, nos proporciona una clave esencial respecto al sentido de la misma.

16. Zavala ha sostenido con buenas razones que "la narración de esa novela epistolarracionalista está basada en lo que $\mathrm{M}$. Bakhtin llama 'device of not understanding', o punto de vista del extranjero que no comprende lo que ve" (pág. 351). 
Concluido el aprendizaje -aunque, por supuesto, podría haber sido más extenso o más breve, la vida continúa para el joven Gazel.

También se ha dicho que Nuño Núñez es el alter ego de Cadalso, como se había dicho que Usbek era el alter ego de Montesquieu. Conroy Jr. (pp. 30-32) ha aportado razones más que suficientes para desechar esa identificación demasiado elemental. Pero en el caso del autor de Lettres persanes se disponía de otros textos suyos para rastrear y aislar cierta identidad de opiniones, lo cual no sucede con Cadalso, como reconoce el mismo Abellán (pág. 795). ¿Cómo afirmar, por tanto, que lo que opina Nuño es exactamente lo que opina Cadalso? ¿Acaso no es también cierto que Cadalso opina lo mismo que Ben-Beley y, a veces, que Gazel? ¿Debemos deducir que Cadalso era como Nuño? Creo que esa identificación Cadalso-Nuño es insuficiente en el plano de la realidad, y poco útil si intentamos leer la obra como una ficción novelística.

En este sentido, cobra especial interés la presencia en el texto de las Cartas marruecas de un escrito que tiene Nuño Núñez entre manos: las Observaciones y reflexiones sueltas. Sebold (1974, pág. 225) lo ha utilizado para subrayar la subjetividad de la obra en cuanto que esas Observaciones de Nuño equivalen a las Cartas de Cadalso. A mí me interesa mencionarlas en cuanto elemento metaficcional dentro de la novela, tanto si las Observaciones están ya concluidas como si Nuño está todavía en proceso de escritura. En el texto que estamos leyendo se nos habla de un texto que se está escribiendo (o se ha escrito) y que contiene una poética novelística que coincide plenamente con la de Cartas marruecas. Pero abundando en el tema, conviene recordar esa novela que escribió Cadalso y de la que sólo tenemos el título que él mismo dejó en su Memoria de los acontecimientos más particulares de mi vida: se trata de las Observaciones de un oficial holandés en el nuevamente descubierto Reino de Feliztá (Cadalso 1987, pág. 100). ¿Es casual que tanto el escrito de Nuño -presunto alter de las Cartas- como lo que el mismo Cadalso califica de novela lleven un título tan parecido? Probablemente la única diferencia importante entre ambos textos habría radicado en la estructura narrativa y/o en la elección del narrador.

Importante en esa individualización de los personajes es el cúmulo de detalles que se nos proporcionan sobre Gazel y Nuño. Por ejemplo, Gazel se halla "vestido como estos cristianos, introducido en muchas de sus casas, poseyendo su idioma, y en amistad muy estrecha con un cristiano llamado Nuño Núñez" (pág. 83); padece una enfermedad (pág. 86); reza sus oraciones acostumbradas (pág. 95); habita en una posada; Nuño acompaña a Gazel durante su enfermedad (pág. 86); en otro momento, "sacó de la cartera unos cuadernillos, púsose los anteojos" (pág. 97); había sido capitán de infantería y se hallaba entonces "en frecuentes concursos de gentes de todas clases" (pág. 101); se pone enfermo (pág. 127); tuvo en otro tiempo ideas distintas "a las de quietud y descanso" (pág. 132) que ahora le ocupan; juntos van a su "acostumbrado paseo" (pág. 110); Nuño introduce a Gazel en tertulias (pág. 123); utilizan coches para sus desplazamientos (pág. 127), etc. Y todo ello en un 
contexto temporal del que se proporcionan pocos pero frecuentes indicios: "En este estado quedó esta carta tres semanas ha, cuando me asaltó una enfermedad" (pág. 86); numerosos "ayer", "un día", "a pocos días de mi introducción en algunas casas de esta corte" (pág. 227); y, sobre todo, las referencias a los viajes que Gazel realiza por España y los que ha realizado antes de quedarse en la corte ${ }^{17}$. En suma, una cantidad apreciable de referencias temporales que permiten vislumbrar $-o$ reconstruir mentalmente- la evolución de los personajes a lo largo de la novela.

Respecto al dialogismo de Cartas marruecas, no se trata sólo de lo que Baquero Goyanes (1967, pp. 11-26) ha señalado como perspectivismo del texto, y sobre el que ha vuelto García-Moreno, ni de lo que Zavala (pág. 349) ha llamado "su dialogía comunicativa"; la conflictividad del mismo va más allá de la mera descripción de actitudes distintas. Para eximir al discreto y paciente lector de una larguísima y poco provechosa digresión sobre el dialogismo y la polifonía literaria, bastará citar lo que escribe Angenot sobre el dialogismo: "Terme par lequel V. Chklovski et M. Bakhtine caractérisent le mouvement compositionnel fondamental de Dostö̈evski: Les controverses n'ont pas lieu uniquement entre les personnages; les différents éléments du déroulement thématique sont, eux aussi, d'une certaine manière en conflit: les faits sont diversement interprétés, la psychologie des personagges se contredit; cette forme découle du principe même de Dostoïevski" (V. Chklovski)" ". En el caso de Cartas marruecas, la lectura nos sitúa ante una diversidad de voces que chocan entre sí, que no acaban de armonizarse por medio de ninguna voz de autoridad que imponga la orientación "justa", "adecuada", de las cartas que estamos leyendo o hemos leído. Una falta de orientación que se revela no sólo en lo que se dice, sino también en lo que se silencia. Así, Gazel no hace ningún comentario ante lo que dice Nuño sobre la campaña de Hernán Cortés y su comparación con los traficantes de esclavos. Es lo que Arce (pág. 40) afirma al decir que "no hay un sistema coherente de actitudes morales o críticas". Por supuesto que nosotros como lectores podemos extraer cualquier coherencia que se nos antoje y atribuírsela al autor, pero en ese proceso nos alejamos de la historia viva de los personajes ficticios. Porque se trata, en efecto, de personajes que han vivido y expuesto su visión de las cosas, una visión contradictoria, enfrentada, sin síntesis posible; y son personajes cuyo futuro postextual no está determinado por el curso de la acción novelística.

Lo más destacado, sin embargo, es la conflictividad evidente que resulta de contrastar las más o menos contrapuestas opiniones que los diversos personajes sustentan $-\mathrm{y}$ que, como he señalado, no se ven sometidas a una autoridad

17. Sobre las posibles incoherencias del trayecto y otras dificultades del texto, debe verse Glendinning, 1971.

18. M. Angenot, s.v. dialogisme. Puede verse también la voz polyphinic: "Terme par leque M. Bakhtine caractérise le roman dostö̈evskien: 'le mot/le discours pour Bakhtine n'a pas sa vérité dans un référent extérieur au discours qui'il doit refléter. Mais il ne coïncide pas non plus avec le sujet cartésien, possesseur de son discours, identique à lui-même et se représentant en lui; ce mot, ce discours est comme distribué sur différentes instances discursives qu'un je multiple peut occuper simultanément" (J. Kristeva)". 
superior, aunque sí rebatidas y discutidas en el texto- con la conducta misma que esos personajes tienen. Eso es algo que el mismo Quintana percibió, aunque lo interpretó en sentido muy diferente. Para él, los diferentes conceptos que se expresan en la obra sobre la "fama póstuma" eran algo inaceptable (sobre todo que se la califique de pueril); para mí es uno de los muchos elementos que vienen a realzar ese carácter conflictivo, dialógico y nada unívoco del texto. Es muy significativo y ejemplar de esa conflictividad el concepto de hombre de bien. La definición que se da en el epitafio que BenBeley desearía para sí ha sido esencial para estudiar la noción que se tiene durante el siglo XVIII; pero la pregunta que uno se hace dentro del texto es: ¿qué personaje vive de acuerdo con ese concepto? Desde luego, no Nuño; tampoco Ben-Beley, a pesar de sus declaraciones de buena intención. ¿Tal vez llegará a serlo Gazel? Es posible, pero con eso nos vamos ya fuera del texto. Sí, los personajes tienen una noción más o menos clara de lo que debe ser un hombre de bien, pero ninguno de ellos parece actuar de acuerdo con esa noción. En otros términos $-y$ he ahí una de las claves esenciales, si no la esencial, del carácter novelístico del texto, las conductas de los personajes se encuentran entre sí en un conflicto permanente, lo que obliga al lector a una participación constante para encontrar o construir el posible sentido de una fícción cuya univocidad se le escapa de entre los dedos.

Es evidente que mucho camino se ha recorrido entre Afán de Ribera y Cadalso, partiendo de ciertas premisas que, en alguna medida, resultan ser comunes. Porque si bien parece aceptable que, a pesar de sus elementos novelísticos -que yo más bien calificaría exclusivamente de ficticios, Afán de Ribera no ha ido más allá de escribir una denuncia en clave irónica y forma epistolar de lo que a su parecer debía ser un vicio generalizado, la envergadura y complejidad de la obra de Cadalso lo sitúan con pleno derecho en el ámbito de la novela epistolar dieciochesca.

\section{BIBLIOGRAFÍA}

ABELLÁN, José Luis. 1981. Historia crítica del pensamiento español. Tomo III. Del Barroco a la llustración (Siglos XVII y XVIII), Madrid, Espasa-Calpe.

AFÁN DE RIBERA, Fulgencio. 1887. Virtud al uso y mística a la moda, Madrid, Biblioteca Universal, Colección de los mejores autores antiguos y modernos, tomo CXIV.

AGUILAR PIÑAL, Francisco. 1981. Bibliografía de autores españoles del siglo XVIII, Madrid, CSIC, tomo I.

ALTMAN, Janet Gurkin. 1982. Espistolarity. Approaches to a Form, Columbus, Ohio State University Press.

ÁLVAREZ BARRIENTOS, Joaquín. 1983. "Algunas ideas sobre teoría de la novela en el siglo XVIII en Inglaterra y España", Anales de Literatura Española, II, pp. 3-35.

- 1987-88. "Sobre la institucionalización de la literatura: Cervantes y la novela en las historias literarias del siglo XVIII", Anales Cervantinos, XXV-XXVI, pp. 47-63.

- 1991. La novela del siglo XVIII, Madrid, Júcar. 
ANGENOT, Marc. 1979. Glossaire pratique de la critique contemporaine, LaSalle, Hurtubise HMH.

ARCE, Joaquín. 1983. "Introducción" en José de Cadalso, Cartas marruecas. Noches lúgubres. Madrid, Cátedra, pp. 13-73.

BAQUERO GOYANES, Mariano. 1967. "Perspectivismo y crítica en Cadalso, Larra y Mesonero Romanos", Perspectivismo y contraste, Madrid, Gredos, pp. 11-41.

- 1981. "Introducción” en José Cadalso, Cartas marruecas, Barcelona, Planeta, pp. VII-LXIII.

BOURNEUF, R. y R. OUELLET. 1975. La novela, trad. de Enric Sullà, Barcelona, Ariel.

CABANES, Yves. 1954. Le faux dévot dans Afán de Ribera: "Virtud al uso y mística a la moda". París, Fac. des Lettres.

CADALSO, José de. 1983. Cartas marruecas. Noches lúgubres, ed. de Joaquín ARCE, Madrid, Cátedra.

- 1987. Autobiografía. Noches lúgubres, ed. de Manuel CAmarero, Madrid, Castalia.

CASTAÑEDA, Vicente. 1952. Edición de Virtud al uso y mística a la moda, de Fulgencio Afán de Ribera, Madrid, Publicaciones La Arcadia, pp. 9-17.

CONROY, Jr. Peter V. 1992. Montesquieu revisited, New York, Twayne.

ÉTIENVRE, Françoise. 1987. "Lecturas españolas del Quijote en el siglo XVIII", en Actas del coloquio cervantino. Würzburg 1983, ed. de Th. BERCHEM y H. LAITENBERGer, Münster Westfalen, Aschendorffsche, pp. 27-47.

EYMERICH, Nicolau. 1973. Directorium Inquisitorum, traducción y edición de Louis SALAMolins, Le manuel des inquisiteurs, Paris, École pratique des Hautes Études, La Haye, Mouton and Co.

GLENDINNING, Nigel. 1962. Vida y obra de Cadalso, Madrid, Gredos.

_ 1971. "Structure in the Cartas marruecas of Cadalso", en The Varied Pattern: Studies in the 18th. Century, ed. de P. Hughes y D. Williams, Toronto, Hakkert, pp. 51-76.

GOLDZINK, Jean. 1989 (ed.) Charles Louis de Montesquieu. Lettres persanes. Paris, Presses Universitaires de France.

GARCÍA-MORENO BARCO, Francisco. 1991. "El perspectivismo literario y filosófico de las Cartas marruecas de Cadalso", Tropos, 17, pp. 61-70.

MARAVALL, José Antonio. 1966. "De la Ilustración al Romanticismo: el pensamiento político de Cadalso", en Mélanges à la mémoire de Jean Sarrailh, Paris, Centre de Recherches de l'Institut d'Études Hispaniques, tomo II, pp. 81-96.

MAYANS Y SISCAR, Gregorio. 1757. Rhetórica, Valencia, Herederos de Gerónimo Conejos, 2 vols.

- 1972. Vida de Miguel de Cervantes Saavedra, ed. de Antonio Mestre, Madrid, Espasa-Calpe.

MOLIÈRE. 1971. Dom Juan, ed. de León Lejealle, París, Larousse.

MONTESQUIEU, Charles Louis de Secondat, barón de. 1875. (CEuvres complètes, ed. de Edouard Laboulaye, Paris, Garnier.

PÉREZ MAGALLÓN, Jesús. 1991. En torno a las ideas literarias de Mayans, Alicante, Instituto de Cultura "Juan Gil-Albert". 
PIRAS PINA, Rosa y FERRARIS, María Teresa. 1985. "Il punto de vista nelle Cartas marruecas e il cervantismo di Cadalso", Annali dell'Instituto Universitario Orientale, XXVII, pp. 45-68.

PROFETI, María Grazia. 1981. "Morfologia e ideologia in un'opera del secolo XVIII: Virtud al uso y mística a la moda", Quaderni di Lingue e Letterature, VI, pp. 127-151.

QUINTANA, Manuel Josef. 1803. "Literatura: Crítica: Obras del coronel don Josef Cadalso", Variedades de Ciencias, Literatura y Artes, I, pp. 244-320.

RAMÍREZ ARAUJO, Rogelio. 1952. "El cervantismo de Cadalso", Romanic Review, XLIII, pp. 256-265.

ROGERS, Edith. 1986. "El Caballero del Verde Gabán y dos sucesores", Anales Cervantinos, XXIV, pp. 67-76.

SÁNCHEZ-BLANCO, Francisco. 1992. La prosa del siglo XVIII, Madrid, Júcar.

SEBOLD, Rusell, P. 1974. Cadalso: el primer romántico "europeo" de España. Madrid, Gredos.

- 1994a. "La novela social de Cadalso", en prensa.

- 1994b. "Novelas de 'muchos Cervantes': Olavide y el realismo", en este volumen.

SINGER, Godfrey Frank. 1993. The Epistolary Novel. Its Origin, Development, Decline, and Residuary Influence, Philadelphia, University of Pennsylvania Press.

ZAVALA, Iris M. 1985. "Lecturas y lectores en las Cartas marruecas", en Coloquio internacional sobre José Cadalso, Abano Terme, Piovan, pp. 347-363. 